\title{
SYNTHESIS OF THE SODALITE GROUP AND SUBSOLIDUS EQUILIBRIA IN THE SODALITE-NOSELITE SYSTEM
}

\author{
TAKESHI TOMISAKA \\ Department of Mineralogical Sciences and Geology, Faculty \\ of Literature and Science, Yamaguchi University, \\ Yamaguchi, Japan \\ and \\ HANS P. EÜGSTER \\ Department of Geology, The Johns Hopkins University, \\ Baltimore, Maryland, U.S. A.
}

\begin{abstract}
The main end members of the sodalite group, that is, chlorine sodalite, bromine sodalite, iodine sodalite, hydroxylsodalite, carbonate noselite, sulfate noselite, chromate noselite, molybdate noselite and tungstate noselite, were synthesized under hydrothermal and dry conditions, and the cell edges $a_{\mathrm{o}}$ and cell volumes $V$ of these minerals were determined. These minerals can be divided into two subgroups: the sodalite subgroup, which includes chlorine sodalite, bromine sodalite, iodine sodalite and hydroxylsodalite, and the noselite subgroup, which includes carbonate noselite, sulfate noselite, chromate noselite, molybdate noselite and tungstate noselite. The X-ray powder diffraction patterns of the four end members of the sodalite subgroup make their ap. pearance only as $h+k+l=2 n$. Those of five other end members which belong to the noselite subgroup appear as $h+k+l=2 n$ and $h+k+l=2 n+1$.

The dissociation temperatures of chlorine sodalite and sulfate noselite are $1230^{\circ} \pm 5^{\circ} \mathrm{C}$ in chlorine sodalite and $1255^{\circ} \pm 5^{\circ} \mathrm{C}$ in sulfate noselite, and complete solid solution was found to exist between chlorine sodalite $\left(\mathrm{Na}_{8} \mathrm{Al}_{6} \mathrm{Si}_{6} \mathrm{O}_{24} \mathrm{Cl}_{2}\right)$ and sulfate noselite $\left(\mathrm{Na}_{8} \mathrm{Al}_{6} \mathrm{Si}_{6} \mathrm{O}_{24} \mathrm{SO}_{4}\right)$ at temperatures above $1050^{\circ} \mathrm{C}$. Compositions of the chlorine sodalite-sulfate noselite solid solutions were determined from the cell edges $a_{\circ}$ obtained by measuring the shifts of the 211, 310 and 222 reflections $(\mathrm{Cu} K \alpha)$. A solvus of the chlorine sodalite-sulfate noselite series was determined at temperatures below $1050^{\circ} \mathrm{C}$. Polymorphic relationship was discovered in the sulfate noselite in the noselite subgroup.
\end{abstract}




\section{Introduction}

The term 'sodalite group' applies to a family of minerals of the approximate composition, $(\mathrm{R})_{4-8}\left(\mathrm{AlSiO}_{4}\right)_{6}\left(\mathrm{Cl}_{2}, \mathrm{SO}_{4}, \mathrm{CO}_{3},(\mathrm{OH})_{2}, \mathrm{~S}\right)$ where $\mathrm{R}=\mathrm{Na}, \mathrm{Ca}, \mathrm{K}$. The general chemical formula of this mineral group is $\mathrm{R}_{4-8}\left(\mathrm{XSiO}_{4}\right)_{6}(\mathrm{Y})$. The chemical compositions of natural and artificial minerals are as follows:

$$
\begin{aligned}
& \mathrm{R}=\mathrm{Na}, \mathrm{Ca}, \mathrm{K}, \mathrm{Mn}^{+2}, \mathrm{Fe}^{+2}, \mathrm{Zn}, \mathrm{Li}, \mathrm{Ag} \ldots \ldots \ldots \ldots .
\end{aligned}
$$

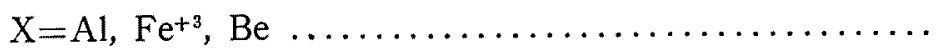

$$
\begin{aligned}
& \mathrm{Y}=\mathrm{Cl}_{2}, \mathrm{Br}_{2},(\mathrm{OH})_{2}, \mathrm{SO}_{4}, \mathrm{CO}_{3}, \mathrm{WO}_{4}, \mathrm{~S} \ldots \ldots \ldots \ldots \ldots \ldots
\end{aligned}
$$

The molecular ratios of $\mathrm{Y}\left(\mathrm{Cl}_{2}, \mathrm{SO}_{4}, \mathrm{CO}_{3},(\mathrm{OH})_{2}, \mathrm{~S}\right)$ in the chemical compositions of natural sodalite and noselite are shown in Table 1

Table 1. Molecular ratios of $\mathrm{Y}\left(\mathrm{Cl}_{2}, \mathrm{SO}_{4}, \mathrm{CO}_{3},(\mathrm{OH})_{2}, \mathrm{~S}\right)$ in natural sodalites and noselites.

\begin{tabular}{|c|c|c|c|c|c|}
\hline $\mathrm{Cl}_{2}$ & $\mathrm{SO}_{4}$ & $\mathrm{CO}_{3}$ & $(\mathrm{OH})_{2}$ & $\mathrm{~S}$ & References \\
\hline 0.6837 & - & 0.0519 & 0.2644 & - & $\begin{array}{l}\text { Medved, D. B. }(1954) \\
\text { Am. Min., 39, } 623 .\end{array}$ \\
\hline 0.7362 & - & - & 0.1543 & 0.1095 & \multirow{13}{*}{$\begin{array}{l}\text { Deer, W. A., Howie, } \\
\text { R. A. \& Zussman, J. } \\
\text { (1963) Rock-Form- } \\
\text { ing Minerals. 4, } 292 .\end{array}$} \\
\hline 0.8815 & - & - & - & 0.1185 & \\
\hline 0.8146 & - & 0.0239 & 0.1615 & - & \\
\hline 0.6903 & - & - & 0.3097 & - & \\
\hline 0.6452 & - & 0.0339 & 0.3209 & - & \\
\hline 1.0000 & - & - & - & - & \\
\hline 0.6116 & - & - & 0.1205 & 0.2679 & \\
\hline 0.0661 & 0.4053 & - & 0.5286 & - & \\
\hline 0.0949 & 0.7773 & - & 0.1278 & - & \\
\hline 0.0564 & 0.4709 & - & 0.4727 & - & \\
\hline 0.0242 & 0.9758 & - & - & - & \\
\hline 0.0659 & 0.7656 & 0.0527 & 0.1158 & - & \\
\hline 0.0408 & 0.8080 & - & - & 0.1512 & \\
\hline 0.0476 & 0.8658 & 0.0866 & - & - & $\begin{array}{l}\text { Barth, T. F. W. (1932). } \\
\text { Am. Min., 17, } 469 .\end{array}$ \\
\hline
\end{tabular}




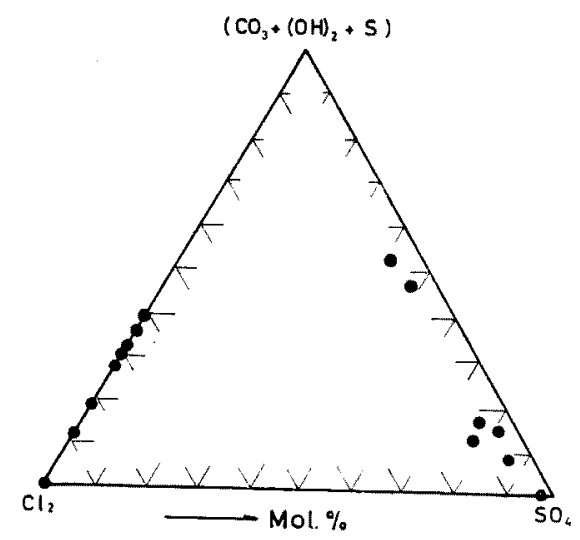

Fig. 1. Chemical compositions of natural minerals in the sodalite group.

Table 2. Compositions and names of end members of natural sodalite group

\begin{tabular}{l|l}
\hline \multicolumn{1}{c|}{ Names } & \multicolumn{1}{c}{ Compositions } \\
\cline { 2 - 2 } sodalite & $\mathrm{Na}_{8}\left(\mathrm{AlSiO}_{4}\right)_{6} \mathrm{Cl}_{2}$ \\
noselite & $\mathrm{Na}_{8}\left(\mathrm{AlSiO}_{4}\right)_{6} \mathrm{SO}_{4}$ \\
hydroxylsodalite & $\mathrm{Na}_{8}\left(\mathrm{AlSiO}_{4}\right)_{6}(\mathrm{OH})_{2}$ \\
carbonate sodalite & $\mathrm{Na}_{8}\left(\mathrm{AlSiO}_{4}\right)_{5} \mathrm{CO}$ \\
sulphur sodalite & $\mathrm{Na}_{8}\left(\mathrm{AlSiO}_{4}\right)_{6} \mathrm{~S}$ \\
\hline
\end{tabular}

and Fig. 1. In defining possible end members of natural sodalite group, five general types must be considered. The compositions and corresponding names of the five probable end members can be represented as in Table 2. The sodium ion is partly replaced by ${ }^{\text {Th }}$. ion. The chemical formula of haüyne is as follows:

$$
(\mathrm{Na}, \mathrm{Ca})_{4-8}\left(\mathrm{AlSiO}_{4}\right)_{6}\left(\mathrm{SO}_{4}, \mathrm{~S}\right)_{1-2} \text {. }
$$

Friedel and Friedel (1890) reported that they had synthesized sodalite by hydrothermal reaction of mixtures of $3 \mathrm{Na}_{2} \mathrm{O}, 3 \mathrm{Al}_{2} \mathrm{O}_{3}, 6 \mathrm{SiO}_{2}$ and $2 \mathrm{NaCl}$, and by heating at about $500^{\circ} \mathrm{C}$ of mixtures of muscovite 
and $\mathrm{NaCl}$ or mixtures of kaolinite and $\mathrm{NaCl}$. Prener and Ward (1950) synthesized sodalite by heating in nitrogen at about $900^{\circ} \mathrm{C}$ of mixtures of $3 \mathrm{Na}_{2} \mathrm{CO}_{3}, 3 \mathrm{Al}_{2} \mathrm{O}_{3}, 6 \mathrm{SiO}_{2}$ and $2 \mathrm{NaCl}$. Barrer and White (1952) synthesized sodalite from sodium aluminosilicate gels and an excess of sodium chloride under hydrothermal condition, and Barrer, Hinds and White (1953) by hydrothermal reaction of analcite with a saturated solution of $\mathrm{NaCl}$. Medved (1954) synthesized sodalite by heating at the temperature of $1060^{\circ} \mathrm{C}, 24 \sim 72$ hours, of stoichiometric mixtures of $\mathrm{Al}_{2} \mathrm{O}_{3}, \mathrm{SiO}_{2}, \mathrm{NaOH}$ and $\mathrm{NaCl}$. Sudo and Matsuoka (1958) synthesized sodalite by hydrothermal reaction at $90^{\circ} \mathrm{C}$ of volcanic glass or ash in solution of $\mathrm{NaOH}(4 \sim 8 \%)$ and $\mathrm{NaCl}(10 \sim 40 \%)$.

Hydroxylsodalite had been synthesized by Borchert and Keidel (1947) by hydrothermal reaction of kaolinite in a concentrated solution of $\mathrm{NaOH}$. Wyart and Michel-Lévy (1949) synthesized hydroxylsodalite by hydrothermal reaction of mixtures of $\mathrm{NaOH}, \mathrm{Al}_{2} \mathrm{O}_{3}$ and $\mathrm{SiO}_{2}$. Barrer and White (1952) synthesized hydroxylsodalite by using sodium aluminosilicate gels, to which was added an excess of $\mathrm{NaOH}$ in solution, and Barrer, Hinds and White (1953) by hydrothermal treatment of analcite. Sudo and Matsuoka (1958) synthesized hydroxylsodalite by hydrothermal reaction of volcanic glass or ash in a solution of $\mathrm{NaOH}(40 \%)$.

Barth (1932) synthesized noselite from mixtures of glass of nepheline composition and $\mathrm{Na}_{2} \mathrm{SO}_{4}$. Barrer and White (1952) synthesized noselite from sodium aluminosilicate gels and an excess of sodium sulfate. Barrer, Hinds and White (1953) synthesized noselite by hydrothermal reaction of analcite with a saturated solution of $\mathrm{Na}_{2} \mathrm{SO}_{4}$.

Other crystalline phases of sodalite structure type have been synthesized by Barrer and Baynham (1956) by heating at $250^{\circ} \mathrm{C}$ aluminous chabazite with fused $\mathrm{AgNO}_{3}$. The formation of tungstate noselite in which the $\mathrm{SO}_{4}$-site in noselite structure was replaced by $\mathrm{WO}_{4}$ molecule has been reported by Saalfeld (1959). Barrer and 
Falconer (1956) reported that they had produced "basic sodalite", "lithium basic sodalite", "silver basic sodalite" and "potassium-rich basic sodalite", by ion exchange as a solid state reaction in feldspathoids. The preparation of $\mathrm{Br}$ - and $\mathrm{Li}$-bearing sodalite was reported by Weiberg (1905), and the replacement of $\mathrm{NaCl}$ by other salts $(\mathrm{NaBr}$, $\mathrm{NaNO}_{3}$ etc.) was demonstrated by Barrer (1954). The preparation of sulfur-bearing sodalite was reported by many investigators.

In this paper, we are reporting the experimental results and crystallographic data from the synthesis under hydrothermal and dry conditions of the main end members of sodalite group: chlorine sodalite, bromine sodalite, iodine sodalite, hydroxylsodalite, carbonate noselite, sulfate noselite, chromate noselite and tungstate noselite. We have determined the variation of cell sizes with its compositions and the solvus curve of the chlorine sodalite-sulfate noselite series, and the dissociation temperatures of chlorine sodalite and sulfate noselite. Also, we have discovered the existence of polymorphic relationship in sulfate noselite.

\section{Experimental Method}

Synthesis of Nepheline:

The starting material for the synthesis of sodium nepheline was sodium bicarbonate $\left(\mathrm{NaHCO}_{3}\right), \gamma$-alumina and cristobalite which were weighed out in stoichiometric proportion. Then the mixture was ground for three hours in acetone. With this mixture, two experiments were made. In one experiment, the mixture was heated at $700^{\circ} \mathrm{C}$ in argon for 10 hours to drive off $\mathrm{CO}_{2}$ and $\mathrm{H}_{2} \mathrm{O}$, and after grinding once again, the mixture was crystallized by heating at $800^{\circ} \mathrm{C}$ for 24 hours. This grinding and heating was repeated three times. In the other experiment, the mixture was heated in sealed $\mathrm{Pt}$ tubes at $700^{\circ} \mathrm{C}$ with a conferring pressure of 2,000 bars, with no water added to the charge. 
Synthesis of Minerals of Sodalite Group:

Experiments were carried out in sealed $\mathrm{Pt}, \mathrm{Au}$ or $\mathrm{Ag}$ capsules, enclosed in a conventional cold pressure vessel (TUTTLE, 1949) or in an autoclave. The charge, i.e., starting materials with water under hydrothermal conditions, and starting materials with no water under dry conditions, was sealed in a thin-walled container, made from Pt, $\mathrm{Au}$ or Ag tubing, with both ends welded. For experiments under atomospheric conditions, sealed $\mathrm{Pt}, \mathrm{Au}$ or $\mathrm{Ag}$ tubes or $\mathrm{Pt}$ crucibles were used.

The products of the experiments were identified by X-ray diffraction and microscope techniques.

\section{Experimental Results}

Sodalites of nine different compositions have been synthesized during the course of this investigation. They are as follows:

$\begin{array}{ll}\text { chlorine sodalite } & \mathrm{Na}_{8}\left(\mathrm{AlSiO}_{4}\right)_{6} \mathrm{Cl}_{2} \\ \text { bromine sodalite } & \mathrm{Na}_{8}\left(\mathrm{AlSiO}_{4}\right)_{6} \mathrm{Br}_{2} \\ \text { iodine sodalite } & \mathrm{Na}_{8}\left(\mathrm{AlSiO}_{4}\right)_{6} \mathrm{I}_{2} \\ \text { hydroxylsodalite } & \mathrm{Na}_{8}\left(\mathrm{AlSiO}_{4}\right)_{6}(\mathrm{OH})_{2} \\ \text { carbonate noselite } & \mathrm{Na}_{8}\left(\mathrm{AlSiO}_{4}\right)_{6} \mathrm{CO}_{3} \\ \text { sulfate noselite } & \mathrm{Na}_{8}\left(\mathrm{AlSiO}_{4}\right)_{6} \mathrm{SO}_{4} \\ \text { tungstate noselite } & \mathrm{Na}_{8}\left(\mathrm{AlSiO}_{4}\right)_{6} \mathrm{WO}_{4} \\ \text { molybdate noselite } & \mathrm{Na}_{8}\left(\mathrm{AlSiO}_{4}\right)_{6} \mathrm{MoO}_{4} \\ \text { chromate noselite } & \mathrm{Na}_{8}\left(\mathrm{AlSiO}_{4}\right)_{6} \mathrm{CrO}_{4}\end{array}$

For dry and hydrothermal runs, a preparation was made by grinding together in acetone a small amount of synthetic nepheline and sodium chloride in chlorine sodalite, synthetic nepheline and sodium bromide in bromine sodalite, synthetic nepheline and sodium iodide in iodine sodalite, synthetic nepheline and sodium hydroxide in hydroxylsodalite, synthetic nepheline and sodium carbonate in carbonate noselite, synthetic nepheline and sodium sulfate in sulfate 
noselite, synthetic nepheline and sodium tungstate in tungstate noselite, synthetic nepheline and sodium molybdate in molybdate noselite, and synthetic nepheline and sodium chromate in chromate noselite. In hydrothermal synthesis, these minerals were synthesized

Table 3. Experimental data on syntheses of chlorine sodalite, bromine sodalite, iodine sodalite and hydroxylsodalite.

\begin{tabular}{l|l|r|r|r|l}
\hline Run & $\begin{array}{c}\text { Starting } \\
\text { materials }\end{array}$ & $\begin{array}{c}\text { Temp. } \\
\left({ }^{\circ} \mathrm{C}\right)\end{array}$ & $\begin{array}{c}\text { Pressure } \\
\text { (bars) }\end{array}$ & $\begin{array}{c}\text { Time } \\
\text { (hours) }\end{array}$ & $\begin{array}{c}\text { Remarks } \\
\text { Optics \& X-ray }\end{array}$ \\
\hline \multicolumn{5}{c}{ Chlorine sodalite } \\
\hline HR-Cl-1 & $\mathrm{Ne}_{60} \mathrm{NaCl}_{40}$ & 850 & 2000 & 130 & Sod $>\mathrm{NaCl}$ \\
$\mathrm{HR}-\mathrm{Cl}-2$ & $\mathrm{Ne}_{60} \mathrm{NaCl}_{40}$ & 750 & 2000 & 240 & Sod $>\mathrm{NaCl}+\mathrm{Nep}$ \\
$\mathrm{HR}-\mathrm{Cl}-3$ & $\mathrm{Ne}_{75} \mathrm{NaCl}_{25}$ & 800 & 2000 & 240 & Sod \\
DR-Cl-1 & $\mathrm{Ne}_{75} \mathrm{NaCl}_{25}$ & 800 & 2000 & 240 & Sod \\
DR-Cl-2 & $\mathrm{Ne}_{25} \mathrm{NaCl}_{75}$ & 750 & 1 & 240 & Sod $+\mathrm{NaCl}$ \\
DR-Cl-3 & $\mathrm{Ne}_{25} \mathrm{NaCl}_{75}$ & 700 & 1 & 240 & Sod $+\mathrm{NaCl}>\mathrm{Nep}$ \\
\hline
\end{tabular}

Bromine sodalite

\begin{tabular}{l|l|r|r|r|l}
\hline DR-Br-1 & $\mathrm{Ne}_{30} \mathrm{NaBr}_{70}$ & 720 & 1 & 28 & Sod $+\mathrm{NaBr}>\mathrm{Nep}$ \\
DR-Br-2 & $\mathrm{Ne}_{30} \mathrm{NaBr}_{70}$ & 800 & 1 & 240 & Sod $+\mathrm{NaBr}$ \\
DR-Br-3 & $\mathrm{Ne}_{75} \mathrm{NaBr}_{25}$ & 750 & 1000 & 240 & Sod \\
\hline
\end{tabular}

Iodine sodalite

\begin{tabular}{l|l|r|r|r|l}
\hline DR-I-1 & $\mathrm{Ne}_{30} \mathrm{NaI}_{70}$ & 650 & 500 & 160 & Sod +NaI $>$ Nep \\
DR-I-2 & $\mathrm{Ne}_{30} \mathrm{NaI}_{70}$ & 710 & 1000 & 160 & Sod $+\mathrm{NaI}>\mathrm{Nep}$ \\
DR-I-3 & $\mathrm{Ne}_{30} \mathrm{NaI}_{70}$ & 760 & 1 & 90 & Sod +NaI \\
DR-I-4 & $\mathrm{Ne}_{75} \mathrm{NaI}_{25}$ & 750 & 1000 & 240 & Sod \\
\hline
\end{tabular}

Hydroxylsodalite

\begin{tabular}{l|l|r|r|r|l}
\hline HR-OH-1 & $\mathrm{Ne}_{50} \mathrm{NaOH}_{50}$ & 90 & 1 & 48 & Sod > Zeolite \\
HR-OH-2 & $\mathrm{Ne}_{50} \mathrm{NaOH}_{50}$ & 150 & 1 & 50 & Sod > Zeolite \\
HR-OH-3 & $\mathrm{Ne}_{75} \mathrm{NaOH}_{25}$ & 800 & 2000 & 240 & Sod \\
DR-OH-1 & $\mathrm{Ne}_{40} \mathrm{NaOH}_{60}$ & 350 & 1 & 120 & Sod +? \\
DR-OH-2 & $\mathrm{Ne}_{75} \mathrm{NaOH}_{25}$ & 800 & 2000 & 240 & Sod \\
\hline
\end{tabular}

HR: hydrothermal run, DR: dry run, Sod: sodalite, Ne: nepheline, Nep: nepheline 
Table 4. Experimental data on syntheses of carbonate noselite, sulfate noselite, chromate noselite, molybdate noselite and tungstate noselite

\begin{tabular}{c|c|c|c|c|c}
\hline Run \# & $\begin{array}{c}\text { Starting } \\
\text { materials }\end{array}$ & $\begin{array}{c}\text { Temp. } \\
\left({ }^{\circ} \mathrm{C}\right)\end{array}$ & $\begin{array}{c}\text { Pres- } \\
\text { sure } \\
\text { (bars) }\end{array}$ & $\begin{array}{c}\text { Time } \\
\text { (hours) }\end{array}$ & $\begin{array}{c}\text { Remarks } \\
\text { Optics \& X-ray }\end{array}$ \\
\hline
\end{tabular}

Carbonate noselite

\begin{tabular}{|c|c|c|c|c|c|}
\hline $\mathrm{HR}-\mathrm{CO}_{3}-1$ & $\mathrm{Ne}_{75}\left(1 / 2 \mathrm{Na}_{2} \mathrm{CO}_{3}\right)_{25}$ & 800 & 2000 & 240 & Nos \\
\hline $\mathrm{DR}-\mathrm{CO}_{3}-1$ & $\mathrm{Ne}_{50}\left(1 /{ }_{2} \mathrm{Na}_{2} \mathrm{CO}_{3}\right)_{50}$ & 720 & 500 & 240 & $\mathrm{Nos}>\mathrm{Na}_{2} \mathrm{CO}_{3}$ \\
\hline $\mathrm{DR}-\mathrm{CO}_{3}-2$ & $\mathrm{Ne}_{75}\left(1 / 2 \mathrm{Na}_{2} \mathrm{CO}_{3}\right)_{25}$ & 800 & 2000 & 240 & Nos \\
\hline \multicolumn{6}{|c|}{ Sulfate noselite } \\
\hline $\mathrm{HR}-\mathrm{SO}_{4}-1$ & $\mathrm{Ne}_{60}\left(1 / 2 \mathrm{Na}_{2} \mathrm{SO}_{4}\right)_{40}$ & 850 & 2000 & 130 & $\mathrm{Nos}>\mathrm{Na}_{2} \mathrm{SO}_{4}$ \\
\hline $\mathrm{HR}-\mathrm{SO}_{4}-2$ & $\mathrm{Ne}_{60}\left(1 / 2 \mathrm{Na}_{2} \mathrm{SO}_{4}\right)_{50}$ & 750 & 2000 & 240 & $\mathrm{Nos}>\mathrm{Na}_{2} \mathrm{SO}_{4}>\mathrm{Nep}$ \\
\hline $\mathrm{HR}-\mathrm{SO}_{4}-3$ & $\mathrm{Ne}_{75}\left(1 / 2 \mathrm{Na}_{2} \mathrm{SO}_{4}\right)_{25}$ & 800 & 2000 & 240 & Nos \\
\hline $\mathrm{DR}-\mathrm{SO}_{4}-1$ & $\mathrm{Ne}_{76}\left(1 / 2{ }_{2} \mathrm{Na}_{2} \mathrm{SO}_{4}\right)_{25}$ & 800 & 2000 & 240 & Nos \\
\hline $\mathrm{DR}-\mathrm{SO}_{4}-2$ & $\mathrm{Ne}_{30}\left(1 / 2 \mathrm{Na}_{2} \mathrm{SO}_{4}\right)_{70}$ & 800 & 1 & 240 & $\mathrm{Nos}+\mathrm{Na}_{2} \mathrm{SO}_{4}$ \\
\hline
\end{tabular}

Chromate noselite

\begin{tabular}{l|l|l|r|r|l}
\hline $\mathrm{DR}-\mathrm{CrO}_{4}-1$ & $\mathrm{Ne}_{20}\left({ }^{1} / 2 \mathrm{Na}_{2} \mathrm{CrO}_{4}\right)_{80}$ & 800 & 1 & 40 & Nos+? \\
$\mathrm{DR}-\mathrm{CrO}_{4}-2$ & $\mathrm{Ne}_{60}\left(1 /{ }_{2} \mathrm{Na}_{2} \mathrm{CrO}_{4}\right)_{40}$ & 800 & 2000 & 240 & Nos+? \\
$\mathrm{DR}-\mathrm{CrO}_{4}-3$ & $\mathrm{Ne}_{75}\left({ }^{2} / \mathrm{Na}_{2} \mathrm{CrO}_{4}\right)_{25}$ & 800 & 2000 & 240 & Nos \\
\hline
\end{tabular}

Molybdate noselite

\begin{tabular}{l|l|l|r|l|l}
\hline $\mathrm{DR}-\mathrm{MoO}_{4}-1$ & $\mathrm{Ne}_{20}\left(1 / 2 \mathrm{Na}_{2} \mathrm{MoO}_{4}\right)_{80}$ & 740 & 1 & 100 & Nos+? \\
$\mathrm{DR}-\mathrm{MoO}_{4}-2$ & $\mathrm{Ne}_{75}\left(1 / 2 \mathrm{Na}_{2} \mathrm{MoO}_{4}\right)_{25}$ & 800 & 2000 & 240 & Nos \\
\hline
\end{tabular}

Tungstate noselite

\begin{tabular}{|c|c|c|c|c|c|}
\hline $\mathrm{DR}-\mathrm{WO}_{4}-1$ & $\mathrm{Ne}_{20}\left(1 / 2 \mathrm{Na}_{2} \mathrm{WO}_{4}\right)_{80}$ & 750 & 600 & 100 & Nos + ? \\
\hline $\mathrm{DR}-\mathrm{WO}_{4}-2$ & $\mathrm{Ne}_{75}\left(1 / 2 \mathrm{Na}_{2} \mathrm{WO}_{4}\right)_{25}$ & 800 & 2000 & 240 & Nos \\
\hline $\mathrm{DR}-\mathrm{WO}_{4}-3$ & $\mathrm{Ne}_{30}\left(1 / 2 \mathrm{Na}_{2} \mathrm{WO}_{4}\right)_{70}$ & 800 & 1 & 100 & Nos $+?$ \\
\hline
\end{tabular}

HR: hydrothermal run, DR: dry run, Ne: nepheline, Nos: noselite.

Nep : nepheline 
by putting in platinum tubes the starting material and distilled water in the approximate weight ratio of $3: 1$.

Experimental data on the synthesis of these minerals are shown in Tables 3 and 4 . All samples were run on an X-ray diffractometer, using $\mathrm{Ni}$-filtered $\mathrm{Cu} K \alpha$ radiation. Silicon was used as an internal standard for determination of lattice parameter. The X-ray powder patterns of these synthetic and natural minerals are given in Tables 5 and 6 . From these results, the sodalite group is divided into the following two subgroups:

$$
\begin{gathered}
\text { Sodalite subgroup } \\
\text { chlorine sodalite } \\
\text { bromine sodalite } \\
\text { iodine sodalite } \\
\text { hydroxylsodalite }
\end{gathered}
$$

$$
\begin{aligned}
& \text { Noselite subgroup } \\
& \text { carbonate noselite } \\
& \text { sulfate noselite } \\
& \text { tungstate noselite } \\
& \text { molybdate noselite } \\
& \text { chromate noselite }
\end{aligned}
$$

The X-ray powder diffraction patterns in the sodalite subgroup make their appearance only as $h+k+l=2 n$. Those of five other end members which belong to the noselite subgroup appear as $h+k+l=2 n$ and $h+k+l=2 n+1$. The cell dimensions and cell volumes of these minerals are shown in Table 7 . These results indicate the variation of cell dimensions with its composition. Tungstate noselite has the largest cell volume, and hydroxylsodalite the smallest cell volume. Also, this variation seems to indicate that the non-silicate portion, that is, anion of the chemical formula, controls the cell size of each of these minerals.

Dissociation Temperatures of Chlorine Sodalite and Sulfate Noselite:

The results from the experiments for determination of the dissociation temperatures of chlorine sodalite and sulfate noselite are given in Table 8 . The chlorine sodalite dissociates at temperatures higher than $1230^{\circ} \pm 5^{\circ} \mathrm{C}$, and sulfate noselite at temperatures higher 
Table 5. X-ray powder diffraction data of chlorine sodalite, bromine sodalite,

\begin{tabular}{|c|c|c|c|c|c|c|}
\hline \multirow[b]{3}{*}{$h k l$} & \multicolumn{6}{|c|}{ Chlorine sodalite } \\
\hline & \multicolumn{2}{|c|}{$\begin{array}{l}\text { Natural sodalite } \\
\text { from the Princers } \\
\text { Mine, Canada }\end{array}$} & \multicolumn{2}{|c|}{$\begin{array}{l}\text { Dry synthesis } \\
P=2000 \text { bars } \\
T=800^{\circ} \mathrm{C}\end{array}$} & \multicolumn{2}{|c|}{$\begin{array}{l}\text { Hydrothermal } \\
\text { synthesis } \\
P_{\mathrm{H}_{2} \mathrm{O}=2000 \text { bars }}=2000^{\circ} \mathrm{C} \\
T=800^{2}\end{array}$} \\
\hline & $d$ & $I$ & $d$ & $I$ & $d$ & $I$ \\
\hline 100 & - & - & - & - & - & - \\
\hline 110 & 6.2580 & 100 & 6.2598 & 90 & 6.2583 & 77 \\
\hline 111 & - & - & - & - & - & - \\
\hline 200 & 4.4306 & 31 & 4.4330 & 25 & 4.4349 & 23 \\
\hline 210 & 3.9722 & 7 & - & - & - & - \\
\hline 211 & 3. 6226 & 130 & 3.6238 & 120 & 3.6236 & 130 \\
\hline 300,221 & - & - & - & - & - & - \\
\hline 310 & 2.8094 & 52 & 2.8089 & 30 & 2.8098 & 30 \\
\hline 311 & - & - & - & - & - & - \\
\hline 222 & 2.5643 & 90 & 2.5643 & 67 & 2.5651 & 58 \\
\hline 320 & - & - & - & - & - & - \\
\hline 321 & 2.3734 & 100 & 2.3729 & 66 & 2.3748 & 58 \\
\hline 400 & 2.2219 & 7 & 2. 2201 & 7 & 2.2201 & 5 \\
\hline 410,322 & - & - & - & - & - & - \\
\hline 411,330 & 2.0925 & 120 & 2.0928 & 100 & 2.0951 & 79 \\
\hline 331 & - & - & - & - & - & - \\
\hline 420 & 1. 9872 & 24 & - & - & 1. 9878 & 12 \\
\hline 332 & 1. 8945 & 15 & 1.8941 & 11 & 1.8947 & 10 \\
\hline 422 & 1. 8135 & 18 & 1.8140 & 11 & 1. 8132 & 10 \\
\hline 510,431 & 1.7425 & 16 & 1.7437 & 10 & 1. 7429 & 9 \\
\hline 520,432 & - & - & - & - & - & - \\
\hline 521 & 1.6222 & 14 & - & - & 1. 6217 & 6 \\
\hline 440 & 1.5711 & 45 & 1.5713 & 6 & 1. 5712 & 26 \\
\hline 522,441 & - & - & - & - & - & - \\
\hline 433,530 & 1.5239 & 25 & 1. 5239 & 25 & 1.5241 & 13 \\
\hline 600,442 & 1. 4813 & 38 & 1.4815 & 21 & 1. 4814 & 19 \\
\hline 532,611 & 1. 4418 & 37 & 1. 4420 & 24 & 1. 4421 & 23 \\
\hline
\end{tabular}


iodine sodalite and hydroxylsodalite. (CuK $K_{\alpha_{1}}, \lambda=1.54050 \AA$, Ni-filtered)

\begin{tabular}{|c|c|c|c|c|c|}
\hline \multicolumn{2}{|c|}{ Bromine sodalite } & \multicolumn{2}{|c|}{ Iodine sodalite } & \multicolumn{2}{|c|}{ Hydroxylsodalite } \\
\hline \multicolumn{2}{|c|}{$\begin{array}{c}\text { Dry synthesis } \\
P=1 \mathrm{~atm} . \\
T=800^{\circ} \mathrm{C}\end{array}$} & \multicolumn{2}{|c|}{$\begin{array}{c}\text { Dry synthesis } \\
P=1 \text { atm. } \\
T=700^{\circ} \mathrm{C}\end{array}$} & \multicolumn{2}{|c|}{$\begin{array}{l}\text { Dry synthesis } \\
P=1 \text { atm. } \\
T=350^{\circ} \mathrm{C}\end{array}$} \\
\hline$d$ & $I$ & $d$ & $I$ & $d$ & $I$ \\
\hline - & - & - & - & - & - \\
\hline 6.3420 & 8 & 6.3781 & 9 & 6.1950 & 86 \\
\hline- & - & - & - & - & - \\
\hline 4.4774 & 16 & 4.5105 & 20 & 4. 3793 & 13 \\
\hline- & - & - & - & - & - \\
\hline 3. 6531 & 130 & 3.6873 & 130 & 3.5742 & 130 \\
\hline- & - & - & - & - & - \\
\hline 2.8321 & 10 & 2.8550 & 3 & 2.7684 & 26 \\
\hline- & - & - & - & - & - \\
\hline 2.5834 & 24 & 2.6037 & 15 & 2.5279 & 39 \\
\hline - & - & - & - & - & - \\
\hline 2. 3902 & 50 & 2.4096 & 43 & 2. 3404 & 31 \\
\hline 2.2380 & 8 & 2.2537 & 13 & 2. 2004 & 5 \\
\hline - & - & 一 & - & - & - \\
\hline 2.1121 & 57 & 2.1258 & 47 & 2.0638 & 26 \\
\hline- & - & - & - & - & - \\
\hline- & - & 2.0150 & 9 & 1.9544 & 5 \\
\hline- & - & - & - & 1.8658 & 8 \\
\hline 1.8230 & 8 & 1.8393 & 5 & 1.7881 & 8 \\
\hline 1.7513 & 7 & 1.7666 & 5 & 1.7164 & 13 \\
\hline- & - & - & - & - & - \\
\hline- & - & 1.6457 & 10 & - & - \\
\hline 1.5811 & 6 & 1.5934 & 9 & 1.5489 & 13 \\
\hline- & - & - & - & - & - \\
\hline 1.5341 & 4 & - & - & 1.5014 & 16 \\
\hline 1.4900 & 13 & 1.5028 & 10 & - & - \\
\hline 1. 4510 & 16 & 1.4624 & 16 & - & - \\
\hline
\end{tabular}


Table 6. X-ray powder diffraction data of sulfate noselite, carbonate $\left(\mathrm{Cu} K_{\alpha_{1}}, \lambda=1.54050 \AA\right.$,

\begin{tabular}{|c|c|c|c|c|c|c|}
\hline \multirow[b]{3}{*}{$h k l$} & \multicolumn{6}{|c|}{ Sulfate noselite } \\
\hline & \multicolumn{2}{|c|}{$\begin{array}{l}\text { Natural noselite } \\
\text { from Rieden, } \\
\text { Eifel, Germany }\end{array}$} & \multicolumn{2}{|c|}{$\begin{array}{l}\text { Dry synthesis } \\
P=2000 \text { bars } \\
T=800^{\circ} \mathrm{C}\end{array}$} & \multicolumn{2}{|c|}{$\begin{array}{c}\text { Hydrothermal } \\
\text { synthesis } \\
P_{\mathrm{H}_{2} \mathrm{O}=2000 \text { bars }}=200^{\circ} \mathrm{C} \\
T=80\end{array}$} \\
\hline & $d$ & $I$ & $d$ & $I$ & $d$ & $I$ \\
\hline 100 & - & - & 9.0544 & 80 & 9.0541 & 47 \\
\hline 110 & 6.4384 & 31 & 6.4025 & 120 & 6.3938 & 74 \\
\hline 111 & - & - & 5.2307 & 21 & 5.2293 & 12 \\
\hline 200 & 4.5559 & 9 & 4. 5296 & 19 & 4.5314 & 12 \\
\hline 210 & - & - & 4. 0543 & 10 & 4.0609 & 7 \\
\hline 211 & 3.7110 & 130 & 3.7040 & 150 & 3. 7020 & 130 \\
\hline 220 & - & - & - & - & - & - \\
\hline 300,221 & - & - & 3.0218 & 25 & 3.0256 & 8 \\
\hline 310 & 2.8809 & 25 & 2.8689 & 61 & 2.8693 & 30 \\
\hline 311 & - & - & - & - & - & - \\
\hline 222 & 2. 6279 & 31 & 2.6186 & 120 & 2.6195 & 70 \\
\hline 320 & - & - & 2.5172 & 23 & 2.5188 & 11 \\
\hline 321 & 2.4348 & 9 & 2.4261 & 28 & 2. 4261 & 12 \\
\hline 400 & 2.2761 & 7 & 2.2705 & 36 & 2.2695 & 16 \\
\hline 410,322 & - & - & 2. 2038 & 66 & - & 一 \\
\hline 411,330 & 2.1458 & 18 & 2.1402 & 7 & 2.1402 & 30 \\
\hline 331 & - & - & - & - & - & - \\
\hline 420 & - & - & - & - & - & - \\
\hline 332 & - & - & 1.9367 & 12 & 1.9362 & 6 \\
\hline 422 & - & - & - & - & - & - \\
\hline 510,431 & 1. 7861 & 11 & 1. 7804 & 43 & 1. 7816 & 16 \\
\hline 520,432 & - & - & 1. 6838 & 6 & - & - \\
\hline 521 & - & - & 1.6583 & 15 & 1. 6586 & 6 \\
\hline 440 & 1. 6093 & 7 & 1.6055 & 32 & 1. 6061 & 12 \\
\hline 522,441 & - & - & 1.5811 & 5 & - & - \\
\hline 433,530 & 1.5612 & 5 & 1.5576 & 14 & 1.5588 & 5 \\
\hline 600,442 & - & - & 1. 5136 & 18 & 1. 5139 & 6 \\
\hline 532,611 & 1. 4762 & 5 & 1. 4732 & 25 & 1. 4739 & 7 \\
\hline
\end{tabular}


noselite, chromate noselite, molybdate noselite and tungstate noselite. Ni-filtered)

\begin{tabular}{|c|c|c|c|c|c|c|c|}
\hline \multicolumn{2}{|c|}{ Carbonate noselite } & \multicolumn{2}{|c|}{$\begin{array}{c}\text { Chromate } \\
\text { noselite }\end{array}$} & \multicolumn{2}{|c|}{$\begin{array}{c}\text { Molybdate } \\
\text { noselite }\end{array}$} & \multicolumn{2}{|c|}{$\begin{array}{c}\text { Tungstate } \\
\text { noselite }\end{array}$} \\
\hline \multicolumn{2}{|c|}{$\begin{array}{c}\text { Dry synthesis } \\
P=2000 \text { bars } \\
T=800^{\circ} \mathrm{C}\end{array}$} & \multicolumn{2}{|c|}{$\begin{array}{c}\text { Dry synthesis } \\
P=1 \text { atm. } \\
T=850^{\circ} \mathrm{C}\end{array}$} & \multicolumn{2}{|c|}{$\begin{array}{c}\text { Dry synthesis } \\
P=1 \text { atm. } \\
T=720^{\circ} \mathrm{C}\end{array}$} & \multicolumn{2}{|c|}{$\begin{array}{c}\text { Dry synthesis } \\
P=1 \text { atm. } \\
T=720^{\circ} \mathrm{C}\end{array}$} \\
\hline$d$ & $I$ & $d$ & $I$ & $d$ & $I$ & $d$ & $I$ \\
\hline 8. 9809 & 10 & 9.1010 & 26 & 9.1415 & 33 & 9.1484 & 33 \\
\hline 6.3692 & 40 & 6.4440 & 32 & 6.4573 & 24 & 6.4571 & 4 \\
\hline- & - & 5.2510 & 8 & 5.2740 & 13 & 5.2795 & 23 \\
\hline- & - & 4.5382 & 8 & 4.5637 & 7 & 4.5692 & 10 \\
\hline- & - & - & - & 4.0860 & 8 & 4.0876 & 18 \\
\hline 3.6834 & 130 & 3.7074 & 130 & 3.7289 & 130 & 3.7290 & 130 \\
\hline- & - & - & - & 3. 3296 & 5 & 3. 2300 & 8 \\
\hline 2.9994 & 107 & - & - & 3.0428 & 11 & 3.0463 & 16 \\
\hline 2.8478 & 24 & 2.8746 & 13 & 2. 8879 & 5 & - & - \\
\hline 2.7113 & 7 & - & - & 2.7518 & 4 & 2.7549 & 9 \\
\hline 2.6044 & 48 & 2.6221 & 42 & 2. 6345 & 31 & 2.6365 & 16 \\
\hline 2.4942 & 20 & 2.5187 & 10 & 2.5314 & 11 & 2.5340 & 13 \\
\hline 2.3953 & 20 & 2.4279 & 10 & 2.4391 & 16 & 2.4414 & 23 \\
\hline 2.2525 & 13 & 2.2725 & 16 & 2. 2816 & 20 & 2. 2832 & 17 \\
\hline 2.1865 & 9 & - & - & - & - & 2. 2164 & 8 \\
\hline 2.1277 & 22 & 2.1425 & 26 & 2. 1510 & 23 & 2.1527 & 26 \\
\hline - & - & - & - & - & - & 2. 0954 & 4 \\
\hline- & - & - & - & - & - & 2.0332 & $4 \mathrm{~B}$ \\
\hline- & - & 1.9379 & 9 & 1.9458 & 11 & 1. 9469 & 10 \\
\hline 1.8375 & 7 & 1.8520 & $3 \mathrm{~B}$ & 1.8635 & 7 & 1.8637 & 7 \\
\hline 1.7068 & 17 & 1.7822 & 13 & 1.7894 & 7 & - & - \\
\hline - & - & - & - & 1.6943 & 5 & 1.6967 & 7 \\
\hline- & - & 1.6604 & 7 & 1.6656 & 12 & 1.6680 & 13 \\
\hline 1.5959 & 15 & 1.6074 & 11 & 1. 6131 & 12 & 1.6148 & 10 \\
\hline - & - & - & - & - & - & 1.5897 & 7 \\
\hline - & - & 1.5594 & 5 & - & - & - & - \\
\hline- & - & 1.5156 & 11 & - & - & - & - \\
\hline 1.4650 & 10 & 1.4752 & 12 & - & 一 & - & - \\
\hline
\end{tabular}


Table 7. The cell dimensions and cell volumes of chlorine sodalite, bromine sodalite, iodine sodalite, hydroxylsodalite, carbonate noselite, sulfate noselite, chromate noselite, molybdate noselite and tungstate noselite.

\begin{tabular}{|c|c|c|c|c|}
\hline \multirow{2}{*}{ Mineral name } & \multicolumn{2}{|c|}{$\begin{array}{l}\text { Condition of } \\
\text { synthesis }\end{array}$} & \multirow{2}{*}{$\begin{array}{c}\text { Cell dimension } \\
(\AA)\end{array}$} & \multirow{2}{*}{$\begin{array}{c}\text { Cell volume } \\
\qquad\left(\AA^{3}\right)\end{array}$} \\
\hline & $\begin{array}{l}\text { Temp. } \\
\left({ }^{\circ} \mathrm{C}\right)\end{array}$ & $\begin{array}{l}\text { Pressure } \\
\text { (bars) }\end{array}$ & & \\
\hline \multirow[t]{2}{*}{ chlorine sodalite } & $\begin{array}{r}800 \\
800 \\
750 \\
1050\end{array}$ & $\begin{array}{c}2000^{*} \\
2000 \\
1 \\
1 * *\end{array}$ & $\begin{array}{l}8.881 \pm 0.002 \\
8.880 \pm 0.002 \\
8.878 \pm 0.002 \\
8.881 \pm 0.002\end{array}$ & $\begin{array}{l}700.46 \\
700.23 \\
699.75 \\
700.46\end{array}$ \\
\hline & \multicolumn{2}{|c|}{$\begin{array}{l}\text { natural sodalite } \\
\text { from the Princers } \\
\text { Mine, Canada }\end{array}$} & $8.880 \pm 0.002$ & 700.23 \\
\hline bromine sodalite & $\begin{array}{l}750 \\
800\end{array}$ & $\begin{array}{r}1000 \\
1\end{array}$ & $\begin{array}{l}8.932 \pm 0.002 \\
8.935 \pm 0.002\end{array}$ & $\begin{array}{l}712.60 \\
713.32\end{array}$ \\
\hline iodine sodalite & $\begin{array}{l}750 \\
760\end{array}$ & $\begin{array}{r}1000 \\
1\end{array}$ & $\begin{array}{l}9.014 \pm 0.002 \\
9.015 \pm 0.002\end{array}$ & $\begin{array}{l}732.41 \\
732.65\end{array}$ \\
\hline hydroxylsodalite & $\begin{array}{l}800 \\
350\end{array}$ & $\begin{array}{r}2000 \\
1\end{array}$ & $\begin{array}{l}8.756 \pm 0.002 \\
8.754 \pm 0.002\end{array}$ & $\begin{array}{l}671.30 \\
670.84\end{array}$ \\
\hline carbonate noselite & $\begin{array}{l}800 \\
800 \\
800\end{array}$ & $\begin{array}{c}2000 * \\
2000 \\
1\end{array}$ & $\begin{array}{l}9.004 \pm 0.002 \\
9.005 \pm 0.002 \\
9.014 \pm 0.002\end{array}$ & $\begin{array}{l}729.97 \\
730.21 \\
732.41\end{array}$ \\
\hline sulfate noselite & $\begin{array}{r}800 \\
800 \\
800 \\
1050\end{array}$ & $\begin{array}{c}2000 * \\
2000 \\
1 \\
1 * *\end{array}$ & $\begin{array}{l}9.075 \pm 0.002 \\
9.074 \pm 0.002 \\
9.090 \pm 0.002 \\
9.090 \pm 0.002\end{array}$ & $\begin{array}{l}747.38 \\
747.13 \\
751.09 \\
751.09\end{array}$ \\
\hline chromate noselite & $\begin{array}{r}800 \\
800 \\
1000\end{array}$ & $\begin{array}{c}2000 \\
1 \\
1 * *\end{array}$ & $\begin{array}{l}9.078 \pm 0.002 \\
9.089 \pm 0.002 \\
9.092 \pm 0.002\end{array}$ & $\begin{array}{l}748.12 \\
750.84 \\
751.58\end{array}$ \\
\hline $\begin{array}{c}\text { molybdate } \\
\text { noselite }\end{array}$ & $\begin{array}{r}800 \\
740 \\
1000\end{array}$ & $\begin{array}{c}2000 \\
1 \\
1 * *\end{array}$ & $\begin{array}{l}9.112 \pm 0.002 \\
9.124 \pm 0.002 \\
9.126 \pm 0.002\end{array}$ & $\begin{array}{l}756.55 \\
759.55 \\
760.05\end{array}$ \\
\hline $\begin{array}{r}\text { tungstate } \\
\text { noselite }\end{array}$ & $\begin{array}{l}800 \\
750 \\
800\end{array}$ & $\begin{array}{r}2000 \\
600 \\
1\end{array}$ & $\begin{array}{l}9.128 \pm 0.002 \\
9.132 \pm 0.002 \\
9.135 \pm 0.002\end{array}$ & $\begin{array}{l}760.54 \\
761.55 \\
762.30\end{array}$ \\
\hline
\end{tabular}

* Hydrothermal synthesis

* Heat treatment of synthetic sample 
Table 8. Experimental data on dissociation temperatures of chlorine sodalite and sulfate noselite.

\begin{tabular}{|c|c|c|c|c|c|c|}
\hline Run & $\begin{array}{l}\text { Starting } \\
\text { materials }\end{array}$ & $\begin{array}{c}\text { Temp. } \\
\left({ }^{\circ} \mathrm{C}\right)\end{array}$ & $\begin{array}{l}\text { Pres- } \\
\text { sure } \\
\text { (atm.) }\end{array}$ & $\begin{array}{c}\text { Time } \\
\text { (hours) }\end{array}$ & $\begin{array}{l}\text { Remarks } \\
\text { Optics \& } \\
\text { X-ray }\end{array}$ & Others \\
\hline Sod-1 & $\begin{array}{l}\text { natural } \\
\text { sodalite* }\end{array}$ & 1000 & 1 & 24 & Sod + Nep & $\begin{array}{l}\text { vessel : } \\
\text { open } \mathrm{Pt} \\
\text { foil }\end{array}$ \\
\hline Sod-2 & $"$ & 950 & 1 & 24 & Sod $>$ Nep & $" \prime$ \\
\hline Sod-3 & $"$ & 1200 & 1 & 10 & Sodalite & $\begin{array}{l}\text { vessel : } \\
\text { sealed } \mathrm{Pt} \\
\text { tube }\end{array}$ \\
\hline Sod -4 & " & 1225 & 1 & 5 & Sodalite & $" 1$ \\
\hline Sod -5 & $"$ & 1235 & 1 & 30 & Carn $>$ Sod & $"$ \\
\hline Sod-6 & $\begin{array}{l}\text { synthetic } \\
\text { sodalite }\end{array}$ & 1225 & 1 & 10 & Sodalite & " \\
\hline Sod -7 & $"$ & 1235 & 1 & 10 & Carn $>$ Sod & $"$ \\
\hline Sod-8 & " & 1250 & 1 & 10 & Carn $>$ Sod & $"$ \\
\hline Sod-9 & $" t$ & 1350 & 1 & 10 & Carn & $"$ \\
\hline Nos -1 & $\begin{array}{l}\text { synthetic } \\
\text { noselite }\end{array}$ & 1230 & 1 & 6 & Noselite & $"$ \\
\hline Nos -2 & $" 1$ & 1250 & 1 & 6 & Noselite & $"$ \\
\hline Nos -3 & $"$ & 1260 & 1 & 10 & Carn $>$ Nos & " \\
\hline Nos -4 & $" 1$ & 1275 & 1 & 10 & Carn $>$ Nos & $"$ \\
\hline Nos -5 & " & 1330 & 1 & 10 & Carnegieite & $"$ \\
\hline
\end{tabular}

* Natural sodalite from the Princers Mine, Canada.

Nep: nepheline, Sod: sodalite, Nos: noselite, Carn: carnegieite

than $1255^{\circ} \pm 5^{\circ} \mathrm{C}$, in a sealed $\mathrm{Pt}$ tube. But the dissociation reaction in chlorine sodalite occurs even at temperatures below $950^{\circ} \mathrm{C}$ in an open tuke.

\section{The Sodalite-Noselite Series}

Change of Cell Sizes with its Composition:

Solid solution members of the chlorine sodalite-sulfate noselite series were synthesized at temperatures from $1050^{\circ}$ to $1100^{\circ} \mathrm{C}$, in sealed $\mathrm{Pt}$ tubes (Table 9). The products were examined by microscope 


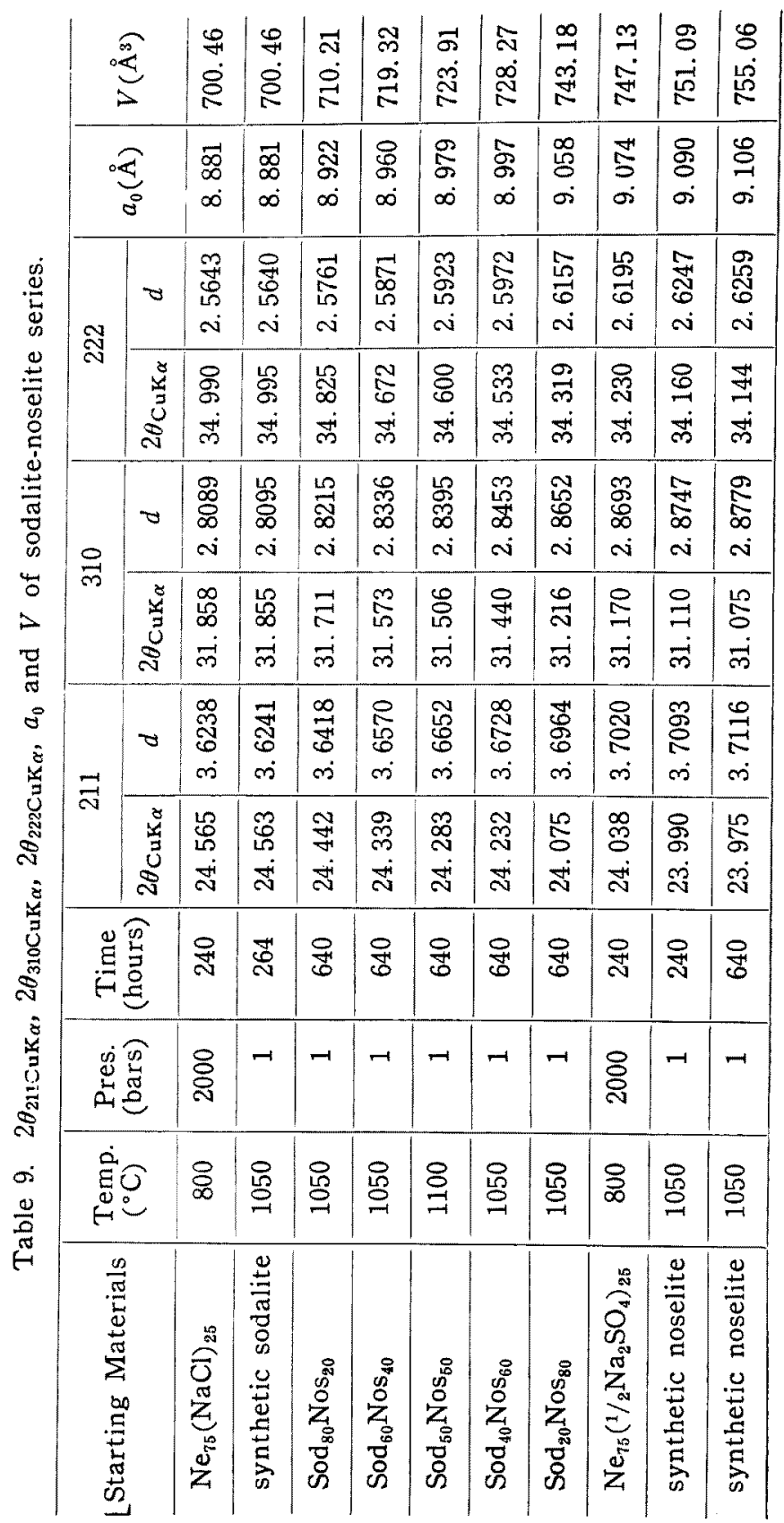


and by X-ray powder diffraction to ascertain that only one phase was present.

The complete solid solution was found to exist between chlorine

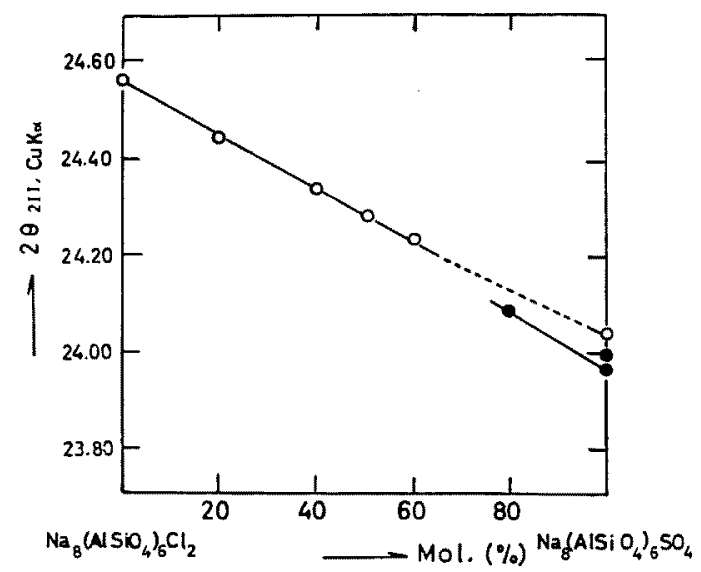

Fig. 2A. X-ray calibration curves for reflections $2 \theta_{211}$. Cu $\mathrm{K} \alpha$ against compositions in the chlorine sodalite-sulfate noselite series. Data from Table 9.

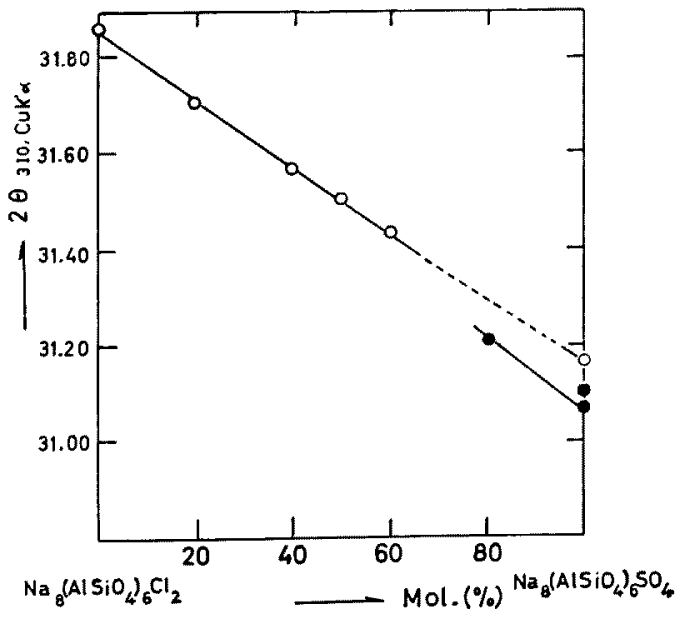

Fig. 2B. X-ray calibration curves for reflections $2 \theta_{210}$. Cu $K_{\alpha}$ against compositions in the chlorine sodalite-sulfate noselite series. Data from Table 9. 


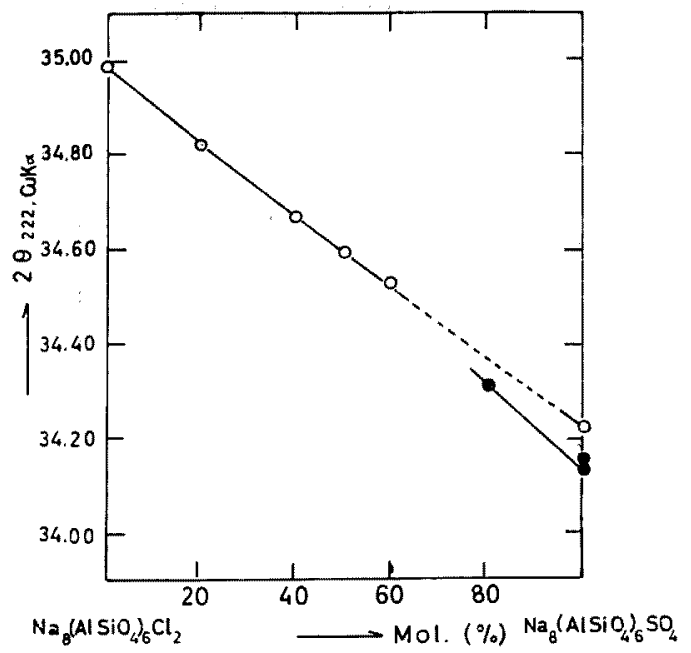

Fig. 2C. X-ray calibration curves for reflections $2 \theta_{222 .}$ Cu K $\alpha$ against compositions in the chlorine sodalite-sulfate noselite series. Data from Table 9 .

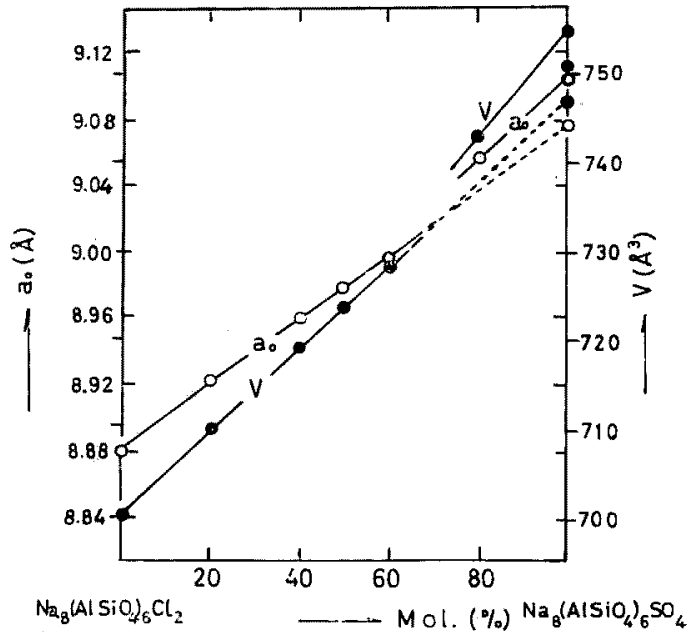

Fig. 3. Changes of cell edges and cell volumes against compositions in the chlorine sodalite-sulfate noselite series. Data from Table 9. 
sodalite and sulfate noselite at the temperature of $1050^{\circ} \mathrm{C}$. The cell dimensions were determined by measuring distances between the peaks on an X-ray powder diffractometer pattern, taken at room temperature, from the internal standard silicon 111 peak, CuK $\alpha 2 \theta=$ $28.465^{\circ}$, to the sodalite peaks 211,310 and 222 . In Table 9 the value of each $2 \theta$ angle listed is an average of thrice-repeated measurements. Fig. 2 shows the $2 \theta_{211}, 2 \theta_{310}$ and $2 \theta_{222}$ curves versus composition, obtained by plotting the data of Table 9 . In Table 9 the $2 \theta$ values are converted to unit cell dimensions on the basis of the value $\mathrm{Cu}$ $K \alpha, \lambda=1.5418 \AA$, and these unit cell dimensions are shown in Fig. 3 along with cell volumes versus composition in mol percentage.

\section{Chlorine Sodalite-Sulfate Noselite Solvus:}

The experimental results defining the limits of solid solution in the chlorine sodalite-sulfate noselite join are listed in Table 10 and shown in Fig. 4. The pressure was atomospheric pressure except for three hydrothermal experiments at 2 kbars (HR-1, HR-2 and $\mathrm{HR}-3$, at $600^{\circ}, 800^{\circ}$ and $\left.850^{\circ} \mathrm{C}\right)$ in which $\mathrm{Ne}_{75}\left(\mathrm{NaCl}_{50}{ }^{1} /{ }_{2} \mathrm{Na}_{2} \mathrm{SO}_{4}{ }_{50}\right)_{25}$ mixtures were used.

The solvus curve was drawn along the junctions of temperaturecomposition points from two opposite directions, i.e., exsolution and solid solution. Intermediate chlorine sodalite-sulfate noselite solid solutions, produced at temperatures above the solvus, were used as starting materials for exsolution experiments. Then, they were held at temperatures below the solvus, whereupon two phases exsolved. Solid solution experiments were carried out with equal amounts of the synthetic end-members, chlorine sodalite and sulfate noselite, thoroughly mixing them by grinding, and inducing solid solution by holding them at given temperatures. The reactions took place at $600^{\circ} \mathrm{C}$, but at $500^{\circ} \mathrm{C}$ equilibrium was not reached.

The error in the location of the solvus, estimated from the scattered points in Fig. 4 , is $\pm 3 \mathrm{~mol}$ percentage at the sides, and $\pm 10^{\circ} \mathrm{C}$ 
Table 10. Experimental data on determination

\begin{tabular}{|c|c|c|c|c|c|c|}
\hline \multirow[b]{2}{*}{ Run } & \multirow{2}{*}{ Starting Materials } & \multirow{2}{*}{$\begin{array}{l}\text { Temp. } \\
\left({ }^{\circ} \mathrm{C}\right)\end{array}$} & \multirow{2}{*}{$\begin{array}{l}\text { Press. } \\
\text { (bars) }\end{array}$} & \multirow{2}{*}{$\begin{array}{c}\text { Time } \\
\text { (hours) }\end{array}$} & \multicolumn{2}{|c|}{211} \\
\hline & & & & & $2 \theta$ CuK $\alpha$ & $d$ \\
\hline HR-1 & $\begin{array}{l}\mathrm{Ne}_{75}\left(\mathrm{NaCl}_{50} \cdot\right. \\
\left.{ }_{1 / 2} \mathrm{Na}_{2} \mathrm{SO}_{450}\right)_{25}\end{array}$ & 600 & 2000 & 240 & $\begin{array}{l}24.550 \\
24.058 \\
\end{array}$ & $\begin{array}{l}3.6260 \\
3.6990 \\
\end{array}$ \\
\hline HR-2 & " & 800 & 2000 & 240 & $\begin{array}{l}24.542 \\
24.080\end{array}$ & $\begin{array}{l}3.6271 \\
3.6957\end{array}$ \\
\hline $\mathrm{HR}-3$ & $"$ & 850 & 2000 & 240 & $\begin{array}{l}24.539 \\
24.110 \\
\end{array}$ & $\begin{array}{l}3.6275 \\
3.6911 \\
\end{array}$ \\
\hline$\overline{\mathrm{DR}-\mathrm{M} 1}$ & $\operatorname{Sod}_{50}+\operatorname{Nos}_{50}$ & 600 & 1 & 720 & $\begin{array}{l}24.540 \\
24.053 \\
\end{array}$ & $\begin{array}{l}3.6274 \\
3.6998 \\
\end{array}$ \\
\hline $\mathrm{DR}-\mathrm{U} 1$ & $\left(\operatorname{Sod}_{60} \operatorname{Nos}_{50}\right)_{\mathrm{ss}}$ & 600 & 1 & 720 & $\begin{array}{l}24.521 \\
24.081 \\
\end{array}$ & $\begin{array}{l}3.6302 \\
3.6955 \\
\end{array}$ \\
\hline $\mathrm{DR}-\mathrm{M} 2$ & $\operatorname{Sod}_{50}+\operatorname{Nos}_{50}$ & 700 & 1 & 720 & $\begin{array}{l}24.540 \\
24.061 \\
\end{array}$ & $\begin{array}{l}3.6274 \\
3.6985\end{array}$ \\
\hline DR-U2 & $\left(\operatorname{Sod}_{50} \operatorname{Nos}_{50}\right)_{\mathrm{ss}}$ & 700 & 1 & 720 & $\begin{array}{l}24.532 \\
24.070 \\
\end{array}$ & $\begin{array}{l}3.6286 \\
3.6972\end{array}$ \\
\hline $\mathrm{DR}-\mathrm{M} 3$ & $\operatorname{Sod}_{50}+\operatorname{Nos}_{50}$ & 800 & 1 & 240 & $\begin{array}{l}24.545 \\
23.980\end{array}$ & $\begin{array}{l}3.6267 \\
3.7109 \\
\end{array}$ \\
\hline DR-U3 & $\left(\operatorname{Sod}_{50} \operatorname{Nos}_{50}\right)_{\mathrm{ss}}$ & 800 & 1 & 240 & $\begin{array}{l}24.520 \\
24.102\end{array}$ & $\begin{array}{l}3.6303 \\
3.6923 \\
\end{array}$ \\
\hline DR-M4 & $\operatorname{Sod}_{50}+\operatorname{Nos}_{50}$ & 800 & $1 \%$ & 408 & $\begin{array}{l}24.527 \\
24.024\end{array}$ & $\begin{array}{l}3.6293 \\
3.7042\end{array}$ \\
\hline$\overline{\mathrm{DR}-\mathrm{U} 4}$ & $\left(\operatorname{Sod}_{50} \operatorname{Nos}_{50}\right)_{s s}$ & 800 & 1 & 408 & $\begin{array}{l}24.521 \\
24.036 \\
\end{array}$ & $\begin{array}{l}3.6302 \\
3.7023 \\
\end{array}$ \\
\hline DR-M5 & $\mathrm{Sod}_{50}+\mathrm{Nos}_{50}$ & 900 & 1 & 240 & $\begin{array}{l}24.506 \\
24.053 \\
\end{array}$ & $\begin{array}{l}3.6323 \\
\text { 3. } 6997\end{array}$ \\
\hline DR-U5 & $\left(\operatorname{Sod}_{50} \operatorname{Nos}_{50}\right)_{s s}$ & 900 & 1 & 240 & $\begin{array}{l}24.445 \\
24.115\end{array}$ & $\begin{array}{l}3.6413 \\
3.6904\end{array}$ \\
\hline $\mathrm{DR}-\mathrm{M} 6$ & $\mathrm{Sod}_{50}+\operatorname{Nos}_{50}$ & 900 & 1 & 720 & $\begin{array}{l}24.469 \\
24.076 \\
\end{array}$ & $\begin{array}{l}3.6378 \\
3.6962 \\
\end{array}$ \\
\hline DR-U6 & $\left(\operatorname{Sod}_{50} \mathrm{Nos}_{50}\right)_{\mathrm{ss}}$ & 900 & 1 & 720 & $\begin{array}{l}24.462 \\
24.082 \\
\end{array}$ & $\begin{array}{l}3.6388 \\
3.6953 \\
\end{array}$ \\
\hline $\mathrm{DR}-\mathrm{M} 7$ & $\operatorname{Sod}_{50}+\operatorname{Nos}_{50}$ & 1000 & 1 & 240 & $\begin{array}{l}24.515 \\
23.995 \\
\end{array}$ & $\begin{array}{l}3.6310 \\
3.7086 \\
\end{array}$ \\
\hline DR-U7 & $\left(\operatorname{Sod}_{50} \operatorname{Nos}_{50}\right)_{s s}$ & 1000 & 1 & 240 & $\begin{array}{l}24.322 \\
24.290\end{array}$ & $\begin{array}{l}3.6594 \\
3.6642 \\
\end{array}$ \\
\hline DR-M8 & $\operatorname{Sod}_{50}+\operatorname{Nos}_{50}$ & 1000 & 1 & 570 & $\begin{array}{l}24.387 \\
24.192\end{array}$ & $\begin{array}{l}3.6498 \\
3.6788 \\
\end{array}$ \\
\hline DR-U8 & $\left(\operatorname{Sod}_{50} \operatorname{Nos}_{50}\right)_{s s}$ & 1000 & 1 & 570 & $\begin{array}{l}24.340 \\
24.224 \\
\end{array}$ & $\begin{array}{l}3.6568 \\
3.6740\end{array}$ \\
\hline DR-M9 & $\operatorname{Sod}_{50}+\operatorname{Nos}_{50}$ & 1050 & 1 & 312 & 24.302 & 3. 6624 \\
\hline DR-U9 & $\left(\operatorname{Sod}_{50} \operatorname{Nos}_{50}\right)_{s s}$ & 1050 & 1 & 312 & 24.304 & 3.6621 \\
\hline DR-M10 & $\operatorname{Sod}_{50}+\operatorname{Nos}_{60}$ & 1050 & 1 & 576 & 24.308 & 3.6615 \\
\hline DR-U10 & $\left(\operatorname{Sod}_{50} N_{o s}\right)_{s s}$ & 1050 & 1 & 576 & 24.306 & 3.6618 \\
\hline DR-M11 & $\operatorname{Sod}_{50}+\operatorname{Nos}_{50}$ & 1025 & 1 & 500 & $\begin{array}{l}24.318 \\
24.285 \\
\end{array}$ & $\begin{array}{l}\text { 3. } 6601 \\
\text { 3. } 6624 \\
\end{array}$ \\
\hline DR-U11 & $\left(\operatorname{Sod}_{50} \operatorname{Nos}_{50}\right)_{\mathrm{ss}}$ & 1025 & 1 & 500 & 24.302 & 3.6624 \\
\hline
\end{tabular}


of solvus of sodalite-noselite series

\begin{tabular}{|c|c|c|c|c|c|}
\hline \multicolumn{2}{|c|}{310} & \multicolumn{2}{|c|}{222} & \multirow{2}{*}{$a_{0}$} & \multirow{2}{*}{ Compositions } \\
\hline $2 \theta_{\text {CuK } \alpha}$ & $d$ & $2 \theta \operatorname{CuK} \alpha$ & $d$ & & \\
\hline $\begin{array}{l}31.837 \\
31.195\end{array}$ & $\begin{array}{l}2.8108 \\
2.8670 \\
\end{array}$ & $\begin{array}{l}34.969 \\
34.255 \\
\end{array}$ & $\begin{array}{l}2.5658 \\
2.6176 \\
\end{array}$ & $\begin{array}{l}8.886 \\
9.064\end{array}$ & $\begin{array}{l}\text { Sod }_{97} \mathrm{Nos}_{3} \\
\operatorname{Nos}_{96} \mathrm{Sod}_{4}\end{array}$ \\
\hline $\begin{array}{l}31.822 \\
31.225 \\
\end{array}$ & $\begin{array}{l}2.8120 \\
2.8644 \\
\end{array}$ & $\begin{array}{r}34.954 \\
34.302 \\
\end{array}$ & $\begin{array}{l}2.5669 \\
2.6142 \\
\end{array}$ & $\begin{array}{l}8.889 \\
9.055\end{array}$ & $\begin{array}{l}\text { Sod }_{95} \text { Nos }_{5} \\
\text { Nos }_{91} \text { Sod }_{9}\end{array}$ \\
\hline $\begin{array}{l}31.817 \\
31.252\end{array}$ & $\begin{array}{l}2.8124 \\
2.8620 \\
\end{array}$ & $\begin{array}{r}34.948 \\
34.345 \\
\end{array}$ & $\begin{array}{l}2.5673 \\
2.6110\end{array}$ & $\begin{array}{l}8.892 \\
9.049\end{array}$ & $\begin{array}{l}\text { Sod }_{94} \text { Nos }_{6} \\
\text { Nos }_{86} \text { Sod }_{14}\end{array}$ \\
\hline $\begin{array}{l}31.830 \\
31.201\end{array}$ & $\begin{array}{l}2.8113 \\
2.8665\end{array}$ & $\begin{array}{l}34.960 \\
34.263 \\
\end{array}$ & $\begin{array}{l}2.5664 \\
2.6171\end{array}$ & $\begin{array}{l}8.888 \\
9.065\end{array}$ & $\begin{array}{l}\operatorname{Sod}_{96} \operatorname{Nos}_{4} \\
\operatorname{Nos}_{96} \operatorname{Sod}_{5}\end{array}$ \\
\hline $\begin{array}{r}31.812 \\
31.232 \\
\end{array}$ & $\begin{array}{r}2.8129 \\
2.8638 \\
\end{array}$ & $\begin{array}{l}34.932 \\
34.302 \\
\end{array}$ & $\begin{array}{l}2.5684 \\
2.6142 \\
\end{array}$ & $\begin{array}{l}8.896 \\
9.054\end{array}$ & $\begin{array}{l}\operatorname{Sod}_{98} \mathrm{Nos}_{7} \\
\operatorname{Nos}_{90} \mathrm{Sod}_{10}\end{array}$ \\
\hline $\begin{array}{l}31.829 \\
31.211\end{array}$ & $\begin{array}{l}2.8114 \\
2.8656 \\
\end{array}$ & $\begin{array}{l}34.955 \\
34.270 \\
\end{array}$ & $\begin{array}{l}2.5668 \\
2.6165 \\
\end{array}$ & $\begin{array}{l}8.888 \\
9.061\end{array}$ & $\begin{array}{l}\operatorname{Sod}_{96} \text { Nos }_{4} \\
\operatorname{Nos}_{94} \operatorname{Sod}_{6}\end{array}$ \\
\hline $\begin{array}{l}31.839 \\
31.222\end{array}$ & $\begin{array}{l}2.8105 \\
2.8646\end{array}$ & $\begin{array}{l}34.947 \\
34.289\end{array}$ & $\begin{array}{l}2.5674 \\
2.6151\end{array}$ & $\begin{array}{l}8.890 \\
9.057\end{array}$ & $\begin{array}{l}\operatorname{Sod}_{95} \operatorname{Nos}_{6} \\
\operatorname{Nos}_{92} \operatorname{Sod}_{8}\end{array}$ \\
\hline $\begin{array}{l}31.832 \\
31.082\end{array}$ & $\begin{array}{l}2.8111 \\
2.8772 \\
\end{array}$ & $\begin{array}{l}34.980 \\
34.150 \\
\end{array}$ & $\begin{array}{l}2.5650 \\
2.6254\end{array}$ & $\begin{array}{l}8.886 \\
9.093\end{array}$ & $\begin{array}{l}\operatorname{Sod}_{96} \operatorname{Nos}_{4} \\
\operatorname{Nos}_{95} \operatorname{Sod}_{5}\end{array}$ \\
\hline $\begin{array}{l}31.794 \\
31.250\end{array}$ & $\begin{array}{l}2.8144 \\
2.8621\end{array}$ & $\begin{array}{l}34.918 \\
34.320\end{array}$ & $\begin{array}{l}2.5694 \\
2.6128\end{array}$ & $\begin{array}{l}8.897 \\
9.047\end{array}$ & $\begin{array}{l}\text { Sod }_{91} \text { Nos }_{9} \\
\operatorname{Nos}_{78} \operatorname{Sod}_{28}\end{array}$ \\
\hline $\begin{array}{l}31.816 \| \\
31.141\end{array}$ & $\begin{array}{l}2.8125 \\
2.8719 \\
\end{array}$ & $\begin{array}{l}34.941 \\
34.231\end{array}$ & $\begin{array}{l}2.5678 \\
2.6194\end{array}$ & $\begin{array}{l}8.892 \\
9.082\end{array}$ & $\begin{array}{l}\text { Sod }_{94} \text { Nos }_{6} \\
\text { Nos }_{91} \text { Sod }_{9}\end{array}$ \\
\hline $\begin{array}{l}31.801 \\
31.157\end{array}$ & $\begin{array}{l}2.8138 \\
2.8705\end{array}$ & $\begin{array}{l}34.931 \\
34.250\end{array}$ & $\begin{array}{l}2.5685 \\
2.6180 \\
\end{array}$ & $\begin{array}{l}8.894 \\
9.077\end{array}$ & $\begin{array}{l}\operatorname{Sod}_{93} \operatorname{Nos}_{7} \\
\text { Nos }_{88} \operatorname{Sod}_{12}\end{array}$ \\
\hline $\begin{array}{l}31.789 \\
31.147\end{array}$ & $\begin{array}{l}2.8148 \\
2.8714\end{array}$ & $\begin{array}{l}34.912 \\
34.271 \\
\end{array}$ & $\begin{array}{l}2.5698 \\
2.6164\end{array}$ & $\begin{array}{l}8.898 \\
9.071\end{array}$ & $\begin{array}{l}\operatorname{Sod}_{91} \text { Nos }_{9} \\
\operatorname{Nos}_{86} \operatorname{Sod}_{14}\end{array}$ \\
\hline $\begin{array}{l}31.718 \\
31.252\end{array}$ & $\begin{array}{l}2.8210 \\
2.8620\end{array}$ & $\begin{array}{l}34.828 \\
34.362 \\
\end{array}$ & $\begin{array}{l}2.5759 \\
2.6097\end{array}$ & $\begin{array}{l}8.920 \\
9.046\end{array}$ & $\begin{array}{l}\operatorname{Sod}_{81} \operatorname{Nos}_{19} \\
\operatorname{Nos}_{75} \operatorname{Sod}_{25}\end{array}$ \\
\hline $\begin{array}{l}31.746 \\
31.217 \\
\end{array}$ & $\begin{array}{r}2.8185 \\
2.8651 \\
\end{array}$ & $\begin{array}{l}34.862 \\
34.318 \\
\end{array}$ & $\begin{array}{l}2.5734 \\
2.6130 \\
\end{array}$ & $\begin{array}{l}8.912 \\
9.056 \\
\end{array}$ & $\begin{array}{l}\operatorname{Sod}_{85} \operatorname{Nos}_{15} \\
\operatorname{Nos}_{80} \operatorname{Sod}_{20}\end{array}$ \\
\hline $\begin{array}{l}31.740 \\
31.222 \\
\end{array}$ & $\begin{array}{l}2.8191 \\
2.8646 \\
\end{array}$ & $\begin{array}{l}34.852 \\
34.323 \\
\end{array}$ & $\begin{array}{l}2.5742 \\
2.6126 \\
\end{array}$ & $\begin{array}{l}8.913 \\
9.054 \\
\end{array}$ & $\begin{array}{l}\operatorname{Sod}_{84} \operatorname{Nos}_{16} \\
\operatorname{Nos}_{79} \operatorname{Sod}_{21}\end{array}$ \\
\hline $\begin{array}{l}31.790 \\
31.130\end{array}$ & $\begin{array}{l}2.8148 \\
2.8729 \\
\end{array}$ & $\begin{array}{r}34.925 \\
34.188 \\
\end{array}$ & $\begin{array}{l}2.5689 \\
2.6229 \\
\end{array}$ & $\begin{array}{l}8.898 \\
9.085 \\
\end{array}$ & $\begin{array}{l}\operatorname{Sod}_{88} \text { Nos }_{12} \\
\operatorname{Nos}_{92} \text { Sod }_{8}\end{array}$ \\
\hline $\begin{array}{l}31.535 \\
31.510\end{array}$ & $\begin{array}{l}2.8369 \\
2.8391\end{array}$ & $\begin{array}{l}34.648 \\
34.600\end{array}$ & $\begin{array}{l}2.5888 \\
2.5923\end{array}$ & $\begin{array}{l}8.967 \\
8.977\end{array}$ & $\begin{array}{l}\operatorname{Sod}_{57} \operatorname{Nos}_{48} \\
\operatorname{Nos}_{51} \operatorname{Sod}_{49}\end{array}$ \\
\hline $\begin{array}{l}31.641 \\
31.401\end{array}$ & $\begin{array}{l}2.8276 \\
2.8487\end{array}$ & $\begin{array}{l}34.743 \\
34.481\end{array}$ & $\begin{array}{l}2.5820 \\
2.6010\end{array}$ & $\begin{array}{l}8.940 \\
9.007\end{array}$ & $\begin{array}{l}\operatorname{Sod}_{70} \mathrm{Nos}_{30} \\
\operatorname{Nos}_{65} \operatorname{Sod}_{35}\end{array}$ \\
\hline $\begin{array}{l}31.614 \\
31.431 \\
\end{array}$ & $\begin{array}{l}2.8300 \\
2.8461 \\
\end{array}$ & $\begin{array}{l}34.7 \overline{13} \\
34.525 \\
\end{array}$ & $\begin{array}{l}2.5842 \\
2.5978 \\
\end{array}$ & $\begin{array}{l}8.947 \\
8.997 \\
\end{array}$ & $\begin{array}{l}\operatorname{Sod}_{66} \operatorname{Nos}_{34} \\
\operatorname{Nos}_{60} \operatorname{Sod}_{40}\end{array}$ \\
\hline 31.525 & 2. 8378 & 34.625 & 2.5905 & 8.973 & $\operatorname{Sod}_{54} \operatorname{Nos}_{46}$ \\
\hline 31.525 & 2.8378 & 34.630 & 2.5902 & 8.972 & $\operatorname{Sod}_{54} \operatorname{Nos}_{46}$ \\
\hline 31.540 & 2.8365 & 34.633 & 2.5899 & 8.969 & $\operatorname{Sod}_{55} \operatorname{Nos}_{45}$ \\
\hline 31.520 & 2.8382 & 34.634 & 2.5899 & 8.970 & $\operatorname{Sod}_{54} \operatorname{Nos}_{46}$ \\
\hline $\begin{array}{l}31.554 \\
31.512 \\
\end{array}$ & $\begin{array}{l}2.8352 \\
2.8390 \\
\end{array}$ & $\begin{array}{l}34.647 \\
34.604 \\
\end{array}$ & $\begin{array}{l}2.5889 \\
2.5920 \\
\end{array}$ & $\begin{array}{l}8.966 \\
8.976 \\
\end{array}$ & $\begin{array}{l}\operatorname{Sod}_{67} \text { Nos }_{43} \\
\operatorname{Nos}_{49} \operatorname{Sod}_{51}\end{array}$ \\
\hline 31.521 & 2.8382 & 34.631 & 2.5901 & 8.973 & $\operatorname{Sod}_{53} \operatorname{Nos}_{47}$ \\
\hline
\end{tabular}




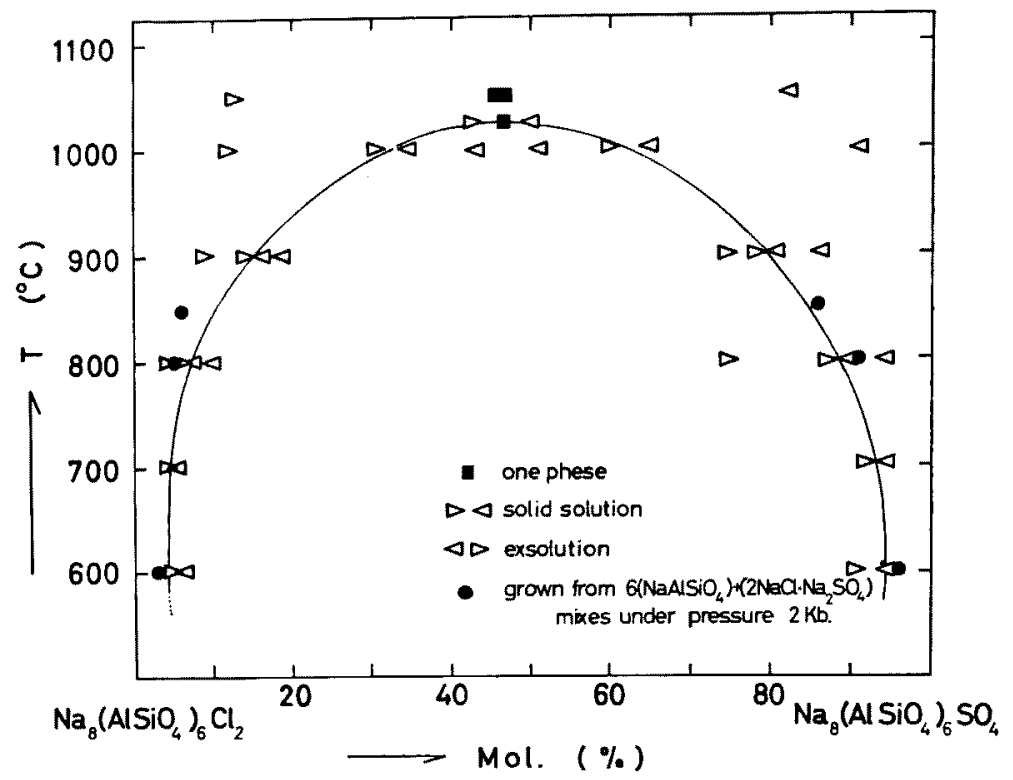

Fig. 4. The chlorine sodalite-sulfate noselite solvus.

at the top. The composition at the top of the solvus is $\operatorname{Sod}_{54} \operatorname{Nos}_{46}$. and the temperature at the top is $1035^{\circ} \pm 10^{\circ} \mathrm{C}$.

Space Groups of Sodalite and Noselite, and Polymorphism of Noselite:

Pauling (1930) reported that he perceived 432 reflexion in a Laue photograph and 210 reflexion in an oscillation photograph, and he showed that the lattice was a primitive cubic one in close approximation to a body-centered cubic one, and chose the space group $P \overline{4} 3 n$ for sodalite. Barth (1932), and Deer, Howie and Zussman (1963) chose the space group $P \overline{4} 3 m$ for sodalite and noselite. Kalaczkowska (1935) chose the space group $I \overline{4} 3 \mathrm{~m}$ for sodalite by taking rolation photographs. Recently, Ueda and Tatekawa (1964) reported that the space group of sodalite is neither $P \overline{4} 3 n$ nor $P \overline{4} 3 m$ but $I \overline{4} 3 m$ by taking Weissenberg photographs of natural sodalites from four different localities.

We perceived weak 210 reflexion on an X-ray powder diffraction pattern of sodalite from the Princers Mine, Canada, but in the X-ray 
T. Tomi saka and H.P. Eugster

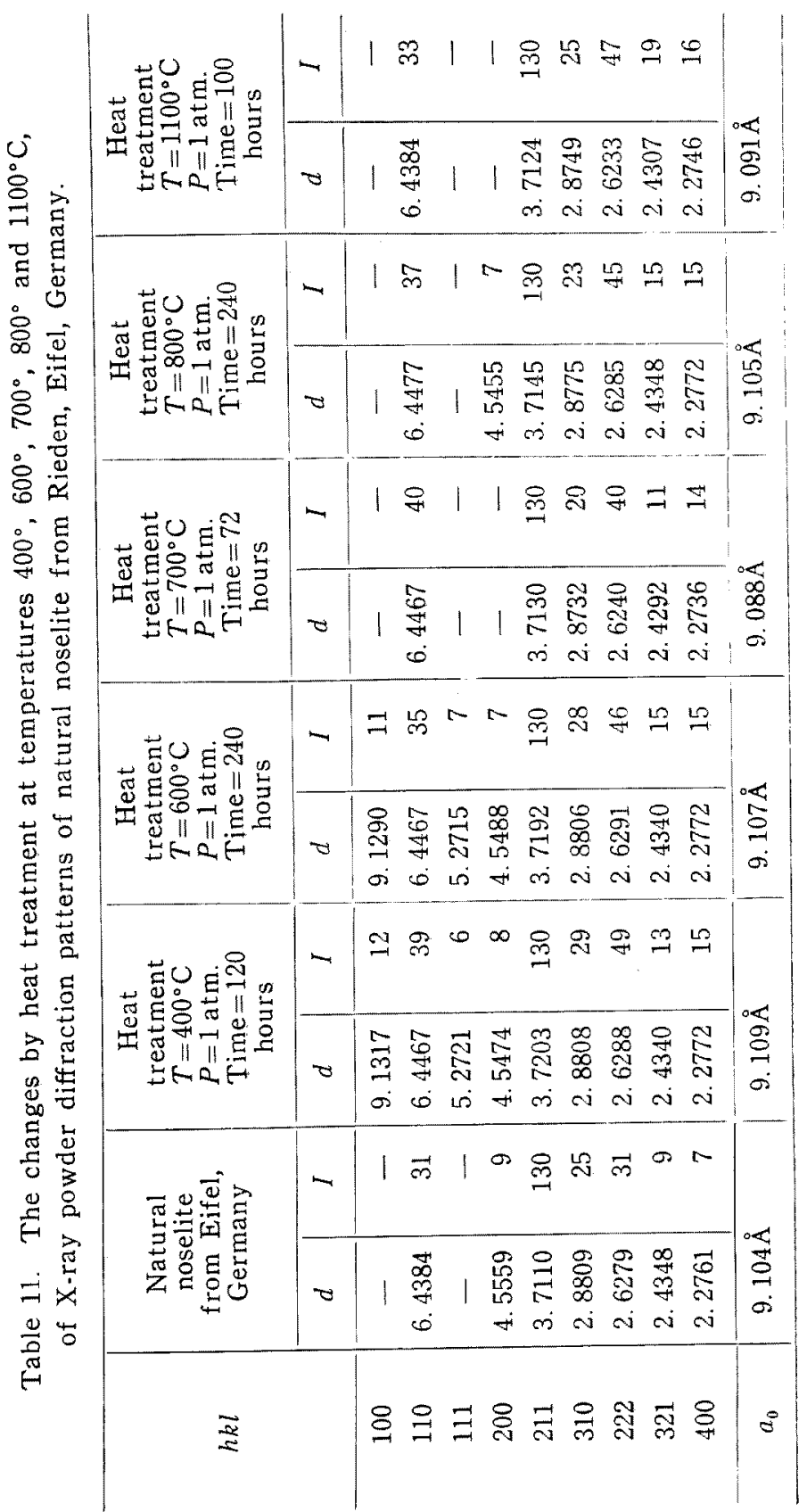


powder diffraction patterns of synthetic minerals of sodalite subgroup only the reflexions of $h+k+l=2 n$ make their appearance (Table 5).

However, in the synthetic minerals which belong to the noselite subgroup the strong reflexions of $h+k+l=2 n+1$ appear in the X-ray powder diffraction patterns, and this fact is a definite reason that the lattice of synthetic noselite subgroup is a primitive one (Table 6). But, in noselite from Rieden, Eifel, Germany, the reflexions of $h+k+$ $l=2 \mathrm{n}+1$ do not appear in the X-ray powder diffraction pattern but appear as weak reflexions in oscillation photographs. The various lattices of the transitional states from a primitive cubic one $(P \overline{4} 3 m)$ to a primitive cubic one in close approximation to body-centered cubic one $(I \overline{4} 3 m)$ seem to be found in noselites. The changes by heat treatment of the X-ray powder diffraction patterns of natural noselite from Rieden, Eifel, are shown in Table 11. This noselite, by annealing at temperatures of $400^{\circ} \sim 600^{\circ} \mathrm{C}$, gives rise to a phase in which appear more distinct reflexions of $h+k+l=2 n+1$.

With regard to the structural relationship between sodalite and noselite, Saalfeld confirmed Machatschki's suggestion (1934) that the $\left(\mathrm{SO}_{4}\right)^{-2}$ ions (one per cell) are distributed in disorder among the two sites, $(000)$ and $(1 / 21 / 21 / 2)$, which are occupied by chlorine in sodalite, and he has shown that the space group of a synthetic tungstate noselite is $P \overrightarrow{4} 3 \mathrm{~m}$, and is the same as that of sulfate noselite. On the other hand, Barth (1932) showed that the $\left(\mathrm{SO}_{4}\right)^{-2}$ ions occupy only the $(000)$ sites and not the $(1 / 21 / 21 / 2)$ sites. It is induced that in Barth's orderly model the reflexions of $h+k+l=2 n+1$ appear distinctly, and in Saalfeld's disorderly model they do not appear. Recently, Kubo and Yamaguchi (1967) gave an experimental datum which confirmed this hypothesis.

The cell dimensions of the synthetic minerals of the noselite subgroup change according to difference of the conditions of syntheses as shown in Tables 7 and 9 ; especially in sulfate noselite the change from $9.074 \AA$ to $9.106 \AA$. But, the cell dimensions of the minerals of 
the sodalite subgroup are nearly constant. This polymorphic relationship in sulfate noselite seems to be the order-disorder polymorphism, which is related to the order-disorder distribution of $\left(\mathrm{SO}_{4}\right)^{-2}$ ions in the two sites, $(000)$ and $(1 / 21 / 21 / 2)$. This problem requires further investigation by means of detailed structural analysis.

\section{Summary}

The results of our experiment can be summarized as follows: 1. The nine end members of sodalite group, that is, chlorine sodalite, bromine sodalite, iodine sodalite, hydroxylsodalite, carbonate noselite, sulfate noselite, chromate noselite, molybdate noselite and tungstate noselite, are synthesized under hydrothermal and dry conditions.

2. These minerals can be divided into two subgroups on the basis of the characteristics of the X-ray powder diffraction patterns and the chemical formulae. The minerals which belong to the sodalite subgroup are chlorine sodalite, bromine sodalite, iodine sodalite and hydroxylsodalite. Those of the noselite subgroup are carbonate noselite, sulfate noselite, chromate noselite, molybdate noselite and tungstate noselite.

3. The variation of cell dimensions with its composition seems to indicate that the non-silicate portion, that is, anion of the chemical formula, controls the cell size of each of these minerals. Tungstate noselite has the largest cell volume, and hydroxylsodalite the smallest cell volume.

4. The dissociation temperatures of chlorine sodalite and sulfate noselite are $1230^{\circ} \pm 5^{\circ} \mathrm{C}$ in chlorine sodalite and $1255^{\circ} \pm 5^{\circ} \mathrm{C}$ in sulfate noselite.

5. The chlorine sodalite-sulfate noselite series make complete solid solution at temperatures above $1050^{\circ} \mathrm{C}$. The solvus of this series was determined at temperatures below $1050^{\circ} \mathrm{C}$ under atmospheric pressure. 6. These experiments indicate that there exist high- and low-tem- 
perature forms of sulfate noselite. It seems that the polymorphism is related to the order-disorder distributions of $\left(\mathrm{SO}_{4}\right)^{-2}$ ions (one per cell) among the two sites, $(000)$ and $(1 / 21 / 21 / 2)$, and there are transitional states between the order form and the disorder form. The structural relation of high-and low-temperature forms in the sulfate noselite is expected to exist in the other minerals which belong to the noselite subgroup, but, to prove it, we must conduct further research by means of detailed structural analysis.

\section{Acknowledgements}

The major portion of this experiment was done in 1965, in the Department of Geology, The Johns Hopkins University. The writers wish to express their thanks to Dr. J. Nolan, then making research at The Johns Hopkins University, for his assistance on numerous experimental problems related to this work, and to Dr. K. Sakurai for furnishing noselite from Rieden, Eifel, Germany. The research was carried out with financial aid which H.P. Eugster received from National Science Foundation, U.S. A., to whom both writers extend their deep gratitude.

\section{REFERENCES}

BARrer, R. M. \& White, E.A. (1952). J. Chem. Soc., 156.

Barrer, R. M., Hinds, L. \& White, E. A. (1953). J. Chem. Soc., 1466.

Barrer, R. M. (1954). Proc. Internat. Symp. Reactivity of Solids, Gothenburg, Pt. 1, 373.

Barrer, R. M. \& Falconer, J.D. (1956). Proc. Roy. Soc., A, 236, 227.

Barrer, R. M. \& Baynham, J. W. (1956). J. Chem. Soc., 2892.

BARTh, T.F.W. (1932). Amer. Min., 17, 466.

BARTh, T.F.W. (1932). Z. Kristallogr., 83, 405.

Borchert, W. \& Keidel, J. (1947). Heidelberger Beiträge Min. Petr., 1, 2. Deer, A. W., Howie, R. A. \& Zussman, J. (1963). Rock Forming Minerals, 4, 289.

Friedel, C. \& Friedel, G. (1890). Bull. Soc. Franc. Min., 13, 182.

Kalaczkowska, M. (1935). Min. Abst, 5, 178. 
Kubo, Y. \& Yamaguchi, G. (1967). J. Miner. Soc. Japan, 8, 235.

MachatschKi, F. (1934). Z Zbl. Miner., A, 136.

Medved, D. B. (1954). Amer. Min., 39, 615.

PAUling, L. (1930). Z. Kristallogr., 74, 213.

Prener, J.S. \& WARd, R. (1950). J. Amer. Chem. Soc., 72, 2780.

SaAlfeld, H. (1959). Neues. Jahr. Min., Monatshefte, 38.

Sudo, T. \& Matsuoka, M. (1958). J. Miner. Soc. Japan, 3, 514.

Tuttle, O.F. (1949). Bull. Geol. Soc. Amer., 60, 1727.

Ueda, T. \& Tatekawa, M. (1964). Memoirs Coll. Sci. Univ. Kyoto, B. $30,41$. WeIBERg, S. (1905). Ann. Univ. Varsovie, 3, 1.

Wyart, J. \& Michel-Levy, M. (1949). J. Amer. Chem. Soc., 72, 2780.

Manuscript received 11 September 1967. 